\title{
Polybrominated diphenyl ethers in combusted residues and soils from an open burning site of electronic wastes
}

\author{
Qian Luo $\cdot$ Ming Hong Wong · Zijian Wang • \\ Zongwei Cai
}

Received: 12 June 2011 / Accepted: 20 October 2012/Published online: 20 November 2012

(C) Springer-Verlag Berlin Heidelberg 2012

\begin{abstract}
Polybrominated diphenyl ethers (PBDEs) are ubiquitous environmental contaminants due to their extensive use. Combusted residue from electronic waste (e-waste) combustion is one of the contamination sources because PBDEs may be deposited in the soil and transported to remote locations. The transport and deposition behaviors of PBDEs released from burning were evaluated by analyzing their concentrations and congener distributions. Total PBDE concentrations were detected in the range from 2379 to $6238 \mathrm{ng} / \mathrm{g}$ (dry weight) in the combusted residue samples collected from a large open burning site and from 247.4 to $1422.3 \mathrm{ng} / \mathrm{g}$ in soil samples collected from different locations close to the open burning site. BDE-209, 183, 153, 99, and 47 were detected in relative high concentrations in both combusted residue and soil samples. The interpretation of the PBDEs concentrations and congener patterns in the combusted residue and soil samples indicated that PBDEs contamination in soil might be a result of e-waste burning and transportation, and deposit of the combusted residue. The total PBDE concentrations decreased significantly with increasing distance from the burned site, suggesting that the
\end{abstract}

Q. Luo $\cdot$ Z. Wang $(\bowtie)$

Research Center for Eco-Environmental Science,

Chinese Academy of Sciences, Beijing 100085,

People's Republic of China

e-mail: wangzj@rcees.ac.cn

Q. Luo $\cdot$ Z. Cai $(\bowtie)$

Department of Chemistry, Hong Kong Baptist University, Kowloon Tong, Hong Kong SAR, People's Republic of China e-mail: zwcai@hkbu.edu.hk

M. H. Wong

Department of Biology, Croucher Institute for Environmental Sciences, Hong Kong Baptist University, Kowloon Tong,

Hong Kong SAR, People's Republic of China combusted activities were the major source of PBDEs in the region and the transportation behavior of lower brominated congeners might not differ from that of higher brominated congeners for short distances.

Keywords Brominated flame retardants (BFRs) . BDE-209 - Open burning · Combusted residue - Soil · GC-MS

\section{Introduction}

Polybrominated diphenyl ethers (PBDEs) are used in large quantities as brominated flame retardants (BFRs) that are added to a variety of consumer and electronic products (Alaee et al. 2003). There are three different PBDEs technical products that are the mixtures of diphenyl ethers with various numbers of bromine atoms on the two rings. Penta-BDE technical products such as Bromkal 70-5DE or Great Lake DE-71, which contains primarily tetra-, penta- and some hexa-BDEs (Sjodin et al. 1998), while the octa-BDE product contains hexa- to nona-brominated congeners and the decaBDE product is almost entirely composed of BDE-209 (Alaee et al. 2003). Penta-BDE mixtures are considered generally more toxic than Octa-BDE, whereas BDE-209 is essentially non-toxic to invertebrates. Penta-BDE and Octa-BDE have been listed in Stockholm Convention in 2009. However, BDE-209 remains legal in most countries and is starting to be banned in some countries (Betts 2008; BSEF 2003). The PBDEs technical products are commonly used in printed circuit boards, components such as connectors, cables, plastic covers and parts of keyboards and monitors in computers (Martin et al. 2004). PBDEs have caused considerable concerns not only because they have been found in the environmental matrices (air, water, sediment, and soil) (de Wit 
2002), biota (fish, birds, marine mammals) (Hites 2004) as well as human blood, milk and adipose (Gill et al. 2004), but also because their concentrations have exponentially increased and some PBDEs congeners possess persistent, bioaccumulative and toxicological properties (Law et al. 2003; Hites 2004).

Soils represent a major sink for these compounds released to the environment (Zou et al. 2007). PBDEs may be bound strongly to soil particles and thus may remain in soil for several years (Palm et al. 2002; Gouin and Harner 2003). Possible degradation of PBDE, particularly the high brominated congeners, in soil has become a concern. Little degradation, however, was reported during atmospheric transport or within the soil because the PBDEs congener composition and distribution measured in background soils closely matched those reported in the technical penta-BDE product (Hassanin et al. 2004; Hale et al. 2006). Airborne congeners of the PBDEs mixture are likely to accumulate in soil as a result of atmospheric deposition. Most of the degradation and metabolism of PBDEs occur in the plant from soils (Mueller et al. 2006; Huang et al. 2010). A recent study has shown that plants could enhance the degradation of PBDEs in soils (Wang et al. 2011).

Obsolete computers and electronic components have been imported into the developing countries of Asia such as China (Terazono et al. 2006). The town of Guiyu located in Guangdong Province has become one of the main centers of e-waste recycling in China. The traditionally ricegrowing community has been turned into an intensive e-waste recycling center since 1995. Humans are exposed to PBDEs from the uncontrolled dismantling, acid treatment, and open burning of this material in the field. The open burning of computer casings and circuit boards stripped of metal parts may produce toxic fumes and combusted residues that contain organic pollutants. Concentrations of PBDEs detected in the Guiyu air were high when compared with those from other cities, which were primarily due to the incomplete combustion of e-wastes (Wong et al. 2007). The uncontrolled recycling activities of e-wastes were found to result in PBDEs entering to the environment (Cai and Jiang 2006; Leung et al. 2007; Luo et al. 2009; Tang et al. 2010). In addition, soils are the main retention for disposal and landfill of e-wastes (Hassanin et al. 2004). Therefore, PBDEs released from e-waste recycling activities may have contaminated nearby rice fields and posted potential risk to human health.

Thus, it is important to investigate the urban emission sources of the three technical products of PBDEs and their relationship with applications in electronic products, as well as this subsequent disposal (Alcock et al. 2003). The combustion of e-waste in the presence of copper from printed circuit boards and computer wiring may lead to higher emissions of PBDEs into the environment (Leung et al. 2007). Studies have confirmed human exposure to PBDEs via inhalation (Harrad et al. 2004) and oral pathways (Hites 2004; Sjödin et al. 2004) leading to health risks. Previous studies on PBDEs concentrations and congener patterns in soil from an e-waste sites indicated that a majority of PBDEs contamination came from disposal (Wang et al. 2005; Cai and Jiang 2006; Zou et al. 2007). Investigation on PBDEs transportability in short distances is needed because the transportation of higher brominated congeners in short distances may differ from that of lower brominated congeners (Zhao et al. 2009).

This study aims to apply developed GC-MS/MS methods for analyzing combusted residue and surface soil samples collected from an open e-waste burning site near a rice field to obtain environmental concentrations and to determine possible sources of contamination and mechanisms of transport and deposition of PBDEs between combusted residues and soils. It is hoped that the results obtained will provide a better understanding of the extent of pollution by e-waste and also contribute useful information for further research on the fate and transport of PBDEs, especially for BDE-209.

\section{Materials and methods}

\section{Chemicals and reagents}

Dichloromethane (DCM), hexane and acetone were purchased from Tedia Company Inc. (Fairfield, OH, USA) and nonane from Fluka (Milwaukee, USA) at pesticide grade. Granular anhydrous sodium sulfate was purchased from Tedia (Fairfield, USA), silica gel $60(0.063-0.200 \mathrm{~mm})$ from Merck (Whitehouse Station, USA), acid alumina (Brockmann I, Standard Grade, 150 mesh) from Aldrich Chemical Co. (Milwaukee, USA), copper powder from UniChem (Surrey, UK) and concentrated sulfuric acid from BDH Laboratory Supplies (Dorset, UK) at analytical grade.

PBDEs standard solutions were purchased from Wellington Laboratories (Ontario, Canada) in 2004. A calibration solution BDE-CVS-E (5 ampoules in 1 kit) contained 19 PBDE congeners (BDE-3, 7, 15, 17, 28, 47, $66,71,77,85,99,100,119,126,138,153,154,183$, and 209). A native standard mix containing BDE-MXD (BDE$17,47,66,100,153,183$, and 209) and ${ }^{13} \mathrm{C}$-labeled PBDEs mix (MBDE-MXC) $\left({ }^{13} \mathrm{C}\right.$-labeled BDE-15, 28, 47, 99, 153, 154, and 183) and ${ }^{13} \mathrm{C}-\mathrm{BDE}-209$ was used to optimize extraction and clean-up procedure for good recovery.

Sample collection

Samples were collected from a large e-waste open burning site (N: 23.3204; E: 116.3688) in Guiyu, Guangdong 
Province, Southeast China, in December 2004 (Fig. 1). Guiyu soils are Ferric Acrisols according to the Soil Map of the People's Republic of China. Guiyu belongs to the sub-tropical climate with an annual average temperature of $21.5^{\circ} \mathrm{C}$, relative humidity of $80 \%$ and a mean annual rainfall of $1721 \mathrm{~mm}$ (Yu et al. 2006). In winter the most common wind is from the north or northeast. Dissolved organic carbon ranged from 73 to $200 \mathrm{mg} / \mathrm{kg}$ among the different sampling sites. Soil organic carbon ranged from 6.1 to $14.35 \%$ and was generally higher at open burning and near open burning sites than that at a nearby rice field and reservoir site (Zhang et al. 2010). Triplicate residue and soil samples were collected at each sampling site. Six combusted residue (CR) samples were taken from different burning areas of a large open burning site. The combusted residue samples contained black and white combusted residues with incomplete combusted plastic particles and chips. The surface soil samples were collected at eight locations from south to north, $100 \mathrm{~m}$ apart, along an 800-m transect away from the open burning site to the Nanyang River (N: 23.3215; E: 116.3692). Soil sample \#1 (S1) was collected from the location closest to the open burning site, while S8 sample was the farthest. The surface soil sampling depth was $0-15 \mathrm{~cm}$ after the removal of the litter layer. The sample was collected by a hand-held corer that was cleaned with distilled water before and after the sample collection. The collected samples were each wrapped in aluminum

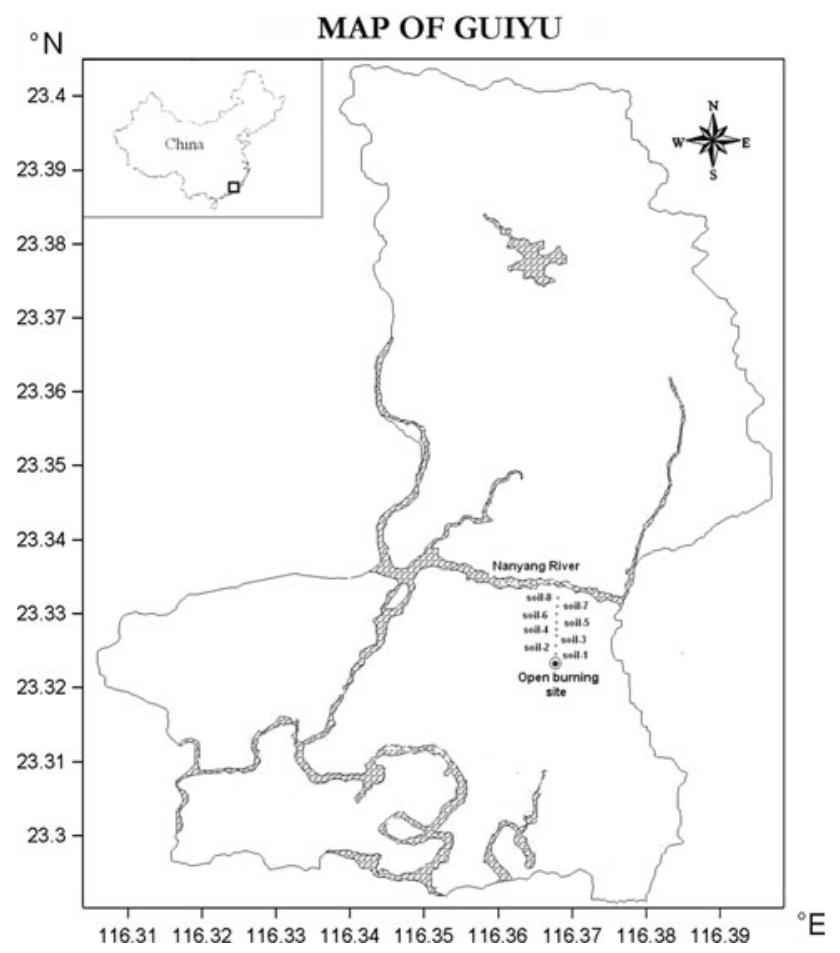

Fig. 1 The sampling locations in Guiyu, Guangdong province, China foil, sealed in a double plastic bag and stored at $4{ }^{\circ} \mathrm{C}$ until analysis.

\section{Extraction and clean-up}

The surface soil or combusted residue samples from each sampling site were thoroughly mixed and freeze-dried, ground and sieved through a $1 \mathrm{~mm}$ sieve. About 5-10 g of the dried sample was mixed with $4 \mathrm{~g}$ of anhydrous sodium sulfate (which was pre-cleaned with DCM and activated at $140{ }^{\circ} \mathrm{C}$ for $24 \mathrm{~h}$ ), and $5 \mathrm{~g}$ of granular copper to remove elemental sulfur. After the spiking with $10-50 \mathrm{ng}$ of MBDE-MXC $\left({ }^{13} \mathrm{C}\right.$-labeled PBDEs $)$, the sample was extracted with $80 \mathrm{~mL}$ of acetone/hexane $(1: 1, \mathrm{v}: \mathrm{v})$ for $16 \mathrm{~h}$ at $68{ }^{\circ} \mathrm{C}$ with Soxhlet extraction. The sample extract was concentrated with rotary evaporator and transferred to a glass bottle with $6 \mathrm{~mL}$ Hexane. The extract was loaded on a clean-up column containing, from top to bottom, $2 \mathrm{~g}$ of anhydrous sodium sulfate, $1 \mathrm{~g}$ of silica gel impregnated with sulfuric acid (44\%), $3 \mathrm{~g}$ of $30 \%$ acid silica gel and $1 \mathrm{~g}$ active silica gel. $N$-hexane $(30 \mathrm{~mL})$ was used for the elution. The eluted solution was loaded onto another column containing $3 \mathrm{~g}$ anhydrous sodium sulfate and $4 \mathrm{~g}$ acid alumina. The column was eluted with $30 \mathrm{~mL}$ hexane/DCM $(7: 3, \mathrm{v}: v)$, which was then concentrated under gentle nitrogen evaporation apparatus at room temperature. The sample was reconstituted in $50 \mu \mathrm{L}$ nonane containing ${ }^{13} \mathrm{C}-\mathrm{BDE}-139$ at $100 \mathrm{pg} / \mu \mathrm{L}$.

\section{GC/ion trap MS analysis}

GC/ion trap MS analysis was performed on a Trace GC/ PolarisQ ion trap mass spectrometer (Thermo Quest, Austin, TX, USA) in MS/MS mode. A DB-5 ms column (30 $\mathrm{m} \times 0.25 \mathrm{~mm}$ I.D., $0.25 \mu \mathrm{m}$ film thickness) was used for the determination of congeners from mono- to heptaBDEs. The temperature program was from $110^{\circ} \mathrm{C}$ to $180{ }^{\circ} \mathrm{C}$ (held for $1 \mathrm{~min}$ ) at $8{ }^{\circ} \mathrm{C} / \mathrm{min}$, then from 180 to $240{ }^{\circ} \mathrm{C}$ (held for $5 \mathrm{~min}$ ) at $2{ }^{\circ} \mathrm{C} / \mathrm{min}$, and then from 240 to $265^{\circ} \mathrm{C}$ (held for $6 \mathrm{~min}$ ) at $2{ }^{\circ} \mathrm{C} / \mathrm{min}$. The GC injector temperature was maintained at $290{ }^{\circ} \mathrm{C}$. The temperatures of the MS ion source and transfer line were kept at $250{ }^{\circ} \mathrm{C}$ and $300{ }^{\circ} \mathrm{C}$, respectively. Sample extract or standard solution $(1 \mu \mathrm{L})$ was injected with a solvent delay set at $6 \mathrm{~min}$. The mass spectrometer was operated with electron impact ionization (EI) mode at source temperature of $250{ }^{\circ} \mathrm{C}$ and electron energy of $70 \mathrm{eV}$. Under the EI-MS conditions, the molecular ions $\left([\mathrm{M}]^{+}\right.$or $\left.[\mathrm{M}+2]^{+}\right)$and fragment ions resulting from the loss of $\mathrm{Br}_{2}$ (i.e., $\left[\mathrm{M}-\mathrm{Br}_{2}+2\right]^{+}$or $\left[\mathrm{M}-\mathrm{Br}_{2}+4\right]^{+}$) were selected as the precursor ions for tandem mass spectrometric analysis. The quantitative ions were selected based on the criteria of peak intensity and ion specificity as well as potential 

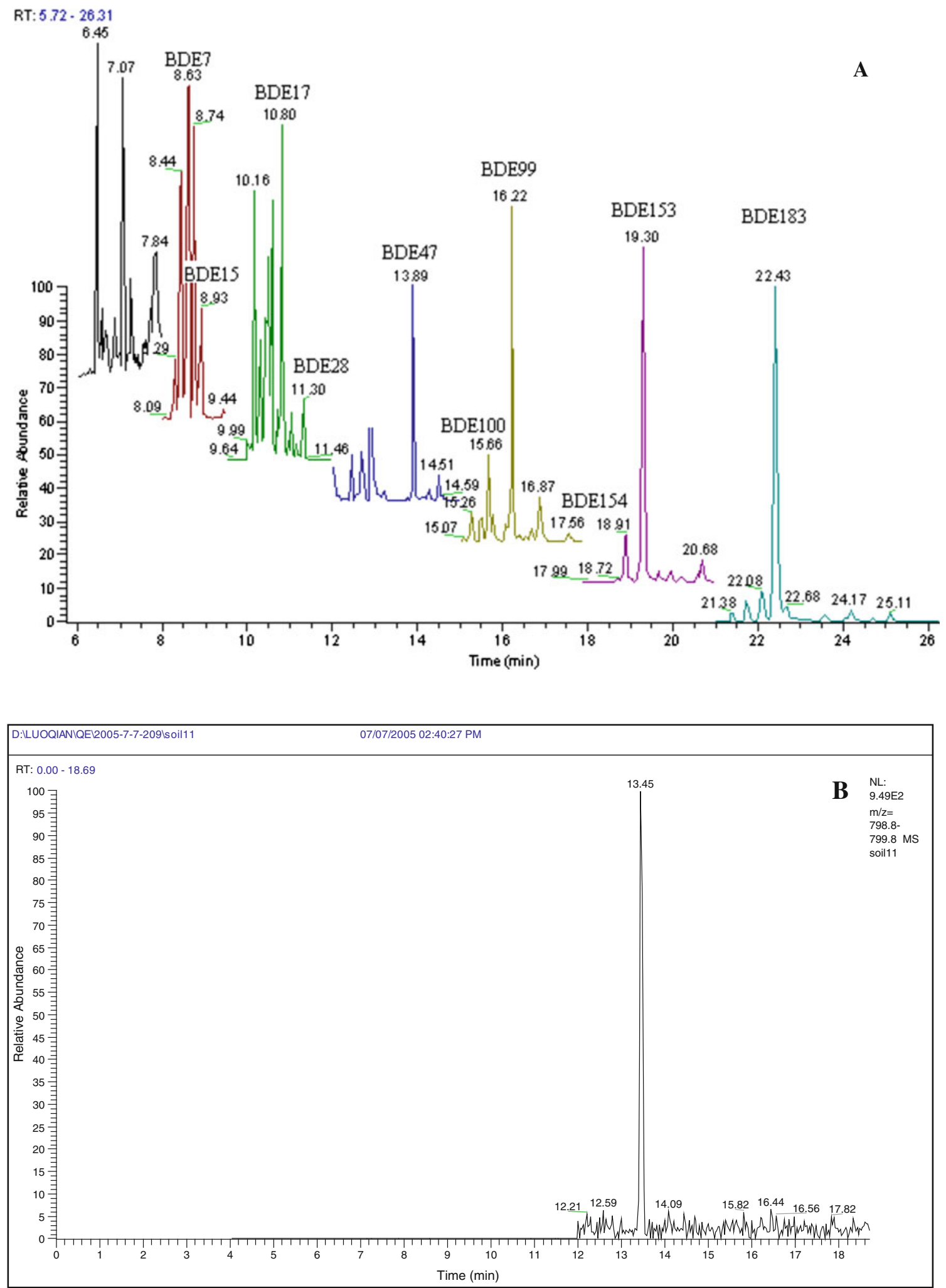

Fig. 2 Chromatograms of selected MS/MS quantification ions of mono to hepta-BDE (a) and the selected ion monitoring chromatogram of deca-BDE (b) from the analysis of a surface soil sample of S2 
interference from other compounds. The important instrumental parameters, i.e., the " $q$ " value, resonant excitation voltage (REV), excitation time (ET) and isolation time (IT) (Luo et al. 2007) were optimized to obtain the best selectivity and sensitivity. GC/MS analysis of BDE-209 was performed on Agilent 5975 GC/MSD with a DB-5 ms column $(15 \mathrm{~m} \times 0.25 \mathrm{~mm}$ I.D., $0.10 \mu \mathrm{m}$ film thickness $)$, with the temperature program from $150{ }^{\circ} \mathrm{C}$ (held for $1 \mathrm{~min}$ ) to $300{ }^{\circ} \mathrm{C}$ (held for $18 \mathrm{~min}$ ) at $30{ }^{\circ} \mathrm{C} / \mathrm{min}$. The MS detector was operated with EI $(70 \mathrm{eV})$ and selected ion monitoring (SIM) of the high abundance ion ( $\mathrm{m} / \mathrm{z} 799.3)$.

Quality assurance and quality control

The extraction recovery data were obtained with the surrogate standards added to the sample prior to the extraction. Recoveries of spiked control sample (surface soil from a field with no detectable PBDEs) ranged from $87 \pm 3.2 \%$ to $103 \pm 4.5 \%$. Recoveries of the ${ }^{13} \mathrm{C}$-labeled internal standards (MBDE-MXC: $8{ }^{13} \mathrm{C}$-labeled BDEs at $10 \mathrm{ng}$ and ${ }^{13} \mathrm{C}-\mathrm{BDE}-209$ at $20 \mathrm{ng}$ ) in all samples ranged from $78 \pm 3.8 \%$ to $113 \pm 4.2 \%$ except BDE-3 which was $50 \%$. The poor recovery of BDE-3 was probably due to its relatively low boiling point, resulting in the loss during the concentration procedure.

The analysis of calibration standards showed peak signal-to-noise ratio $(\mathrm{S} / \mathrm{N})$ of the selected ion better than three for all calibration points. The limits of detections (LOD) were $0.01-0.1 \mathrm{ng} / \mathrm{g}$ for the mono- to hepta-BDEs and $1 \mathrm{ng} / \mathrm{g}$ for deca-BDE. Calibration curve standards for mono- to hepta-BDE (from 1 to $1,000 \mu \mathrm{g} / \mathrm{g}$ ) and decaBDE (from 100 to $10,000 \mu \mathrm{g} / \mathrm{g}$ ) at five concentration levels were subjected to the same extraction and clean-up steps described above. Linear responses with $r^{2}$ of 0.9993-0.9999 and 0.9991 were obtained for mono- to hepta-BDE and deca-BDE, respectively. The identification criteria were both the determination of correct retention time within $<0.2 \mathrm{~min}$ of the expected retention time and the detection of the two confirmation ions at the area ratios within $10 \%$ variation. Retention time shift in the chromatogram was corrected using the isotope internal standard. Quantification was based on isotope internal standard method.

\section{Results and discussion}

The typical chromatograms of PBDEs detected in S2 soil sample obtained from the GC/ion trap MS and GC/MSD analyses are shown in Fig. 2. All targeted PBDEs congeners were detected in the surface soil sample. Table 1 summarizes the concentrations (ng/g dry weight) of the PBDEs in the combusted residue and surface soil samples

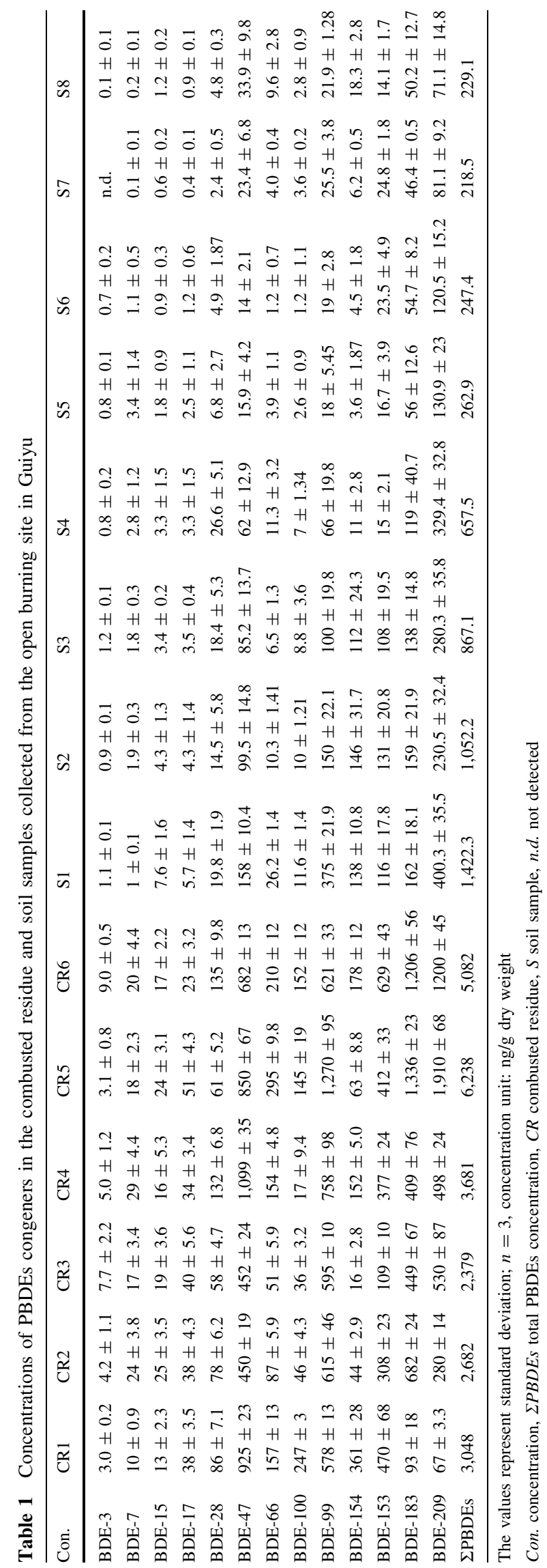


Fig. 3 PBDEs concentrations and congener distributions in the combusted residue $(\mathrm{CR})$ and soil samples from Guiyu. The combusted residue PBDEs data were averaged from the six combusted residue samples collected in the burning site

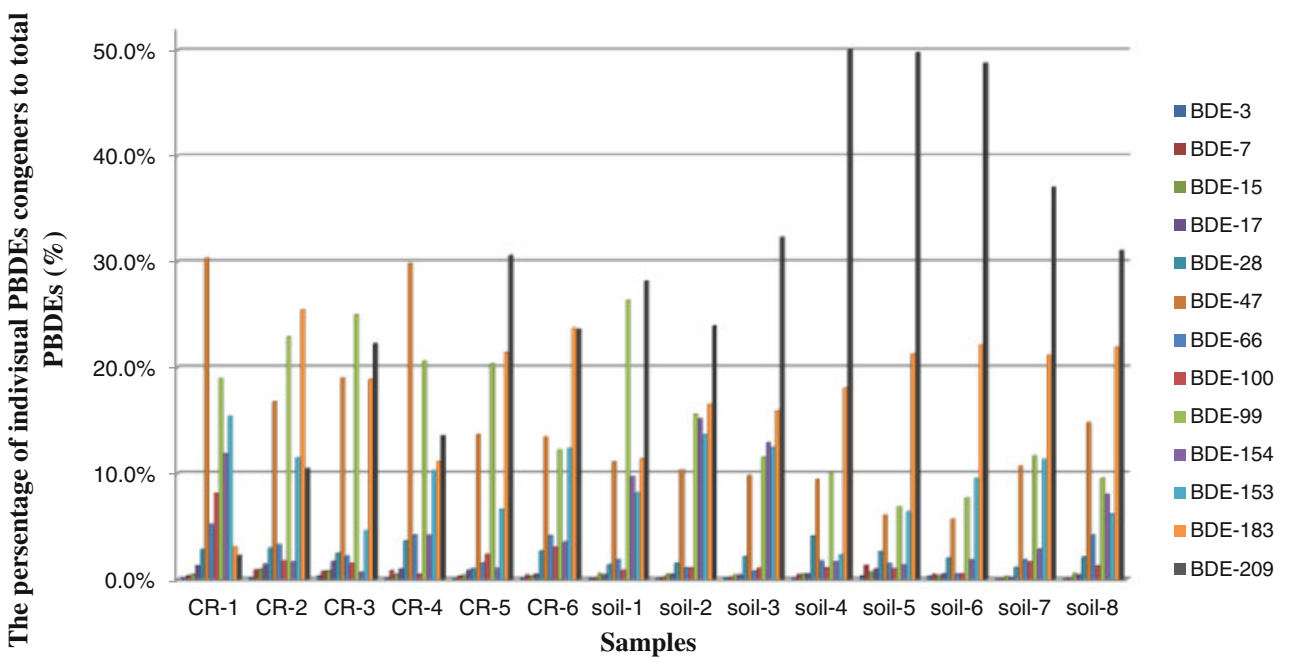

collected from the e-wastes burning site. Concentrations of total PBDEs (from the targeted mono- to hepta-BDEs and deca-BDE) ranged from 2,682 to $6,238 \mathrm{ng} / \mathrm{g}$ with a median of $3,071 \mathrm{ng} / \mathrm{g}$ for the six combusted residue samples from the open burning site where various dismantled and undismantled e-waste materials were combusted. Because the combusted residue samples were collected from different locations with diverse e-waste material, PBDEs were detected at various concentrations. It was found that total PBDEs concentrations in the combusted residue-5 (CR5) sample were greater than at the other sites (Table 1). The results might be explained from the different characteristics of the soil samples. While other combusted residue samples were gray in color, the CR5 sample was black with fine particle residues of plastic and circuit boards, probably due to incomplete combustion. Higher concentrations of PBDEs in CR5 might be attributed to the black particles. On the other hand, the total PBDEs concentrations in CR2 and CR3 were relatively low because some soil was found to be mixed into the combusted residue samples during the sampling. The median level of total PBDEs was similar to the published results of 2909 and $3230 \mathrm{ng} / \mathrm{g}$ in the e-waste recycling sites of Guiyu and Qingyuan, respectively (Gao et al. 2011).

The congener patterns of PBDEs detected in the six combusted residue samples were not the same. However, BDE-209, 183, 47, 99, and 153 were the dominant congeners in all combusted residue samples (Fig. 3), likely due to the same combustion source of commercial products. Concentrations of BDE-209 were 530, 1,910 and 1,200 ng/g in the samples of CR3, CR5 and CR6 with their respective percentage being 22.3, 30.6 and $23.6 \%$ of total PBDEs. BDE-183 represented 18.9 to $25.4 \%$ of the total PBDEs, with the concentrations at $449 \mathrm{ng} / \mathrm{g}$ in CR3, $682 \mathrm{ng} / \mathrm{g}$ in CR2, $1206 \mathrm{ng} / \mathrm{g}$ in CR5 and $1336 \mathrm{ng} / \mathrm{g}$ in CR6. The larger concentration of BDE-183 was probably because this chemical is considered as a marker compound for the octamix PBDEs formulation (Law et al. 2003). Relatively low concentrations of BDE-209 and BDE-183 were detected in $\mathrm{CR} 1$, which also gave a different congener pattern compared to other combusted residue samples. The CR1 sample contained large concentrations of BDE-99, 47, and 153 indicating that this particular sample was probably associated with commercial penta-BDE products. In summary, the analytical results of combusted residue samples (Table 1) indicated that the major e-waste materials treated in the burn site contained the three technical fire-retardant products, with the deca-BDE as the dominant one. The results agree with the fact that deca-BDE is currently the major flame retardant product in use.

The total PBDEs concentrations in the eight soil samples ranged from $218.5 \mathrm{ng} / \mathrm{g}$ (S8) to $1,422.3 \mathrm{ng} / \mathrm{g}(\mathrm{S} 1)$. The concentrations of PBDEs in soil samples were significantly less than those in the burned combusted residue samples. The total PBDE concentrations in this study were similar to previous published results from a printer roller dump site (893-2,890 ng/g), duck pond (263-604 ng/g), and much higher than those from a rice field $(34.7-70.9 \mathrm{ng} / \mathrm{g})$ and reservoir (2.0-6.2 ng/g) (Leung et al. 2007). However, there were much higher concentrations of total PBDEs at 3230 and $2909 \mathrm{ng} / \mathrm{g}$ in surface soils from Qingyuan and Guiyu, respectively (Gao et al. 2011). The observed PBDE concentrations in the environmental samples indicated that the PBDEs contamination around the e-wastes open burning site in Guiyu was serious. The levels of PBDEs in environmental soil from Guiyu was about 1,000 times greater than those determined in the soil samples collected near the foam production facilities using the penta-BDE mixture as flame retardant in the UK and Norway (Wong et al. 2007).

The major concentration pattern of PBDEs in the soil samples was similar to the pattern of combusted residue 
Fig. 4 Relationship between the total PBDEs concentrations and distance from e-wastes open burning site. The distance between samples was $100 \mathrm{~m}$. The PBDEs data in combusted residue (CR) were averaged from the six combusted residue samples collected in the burning site
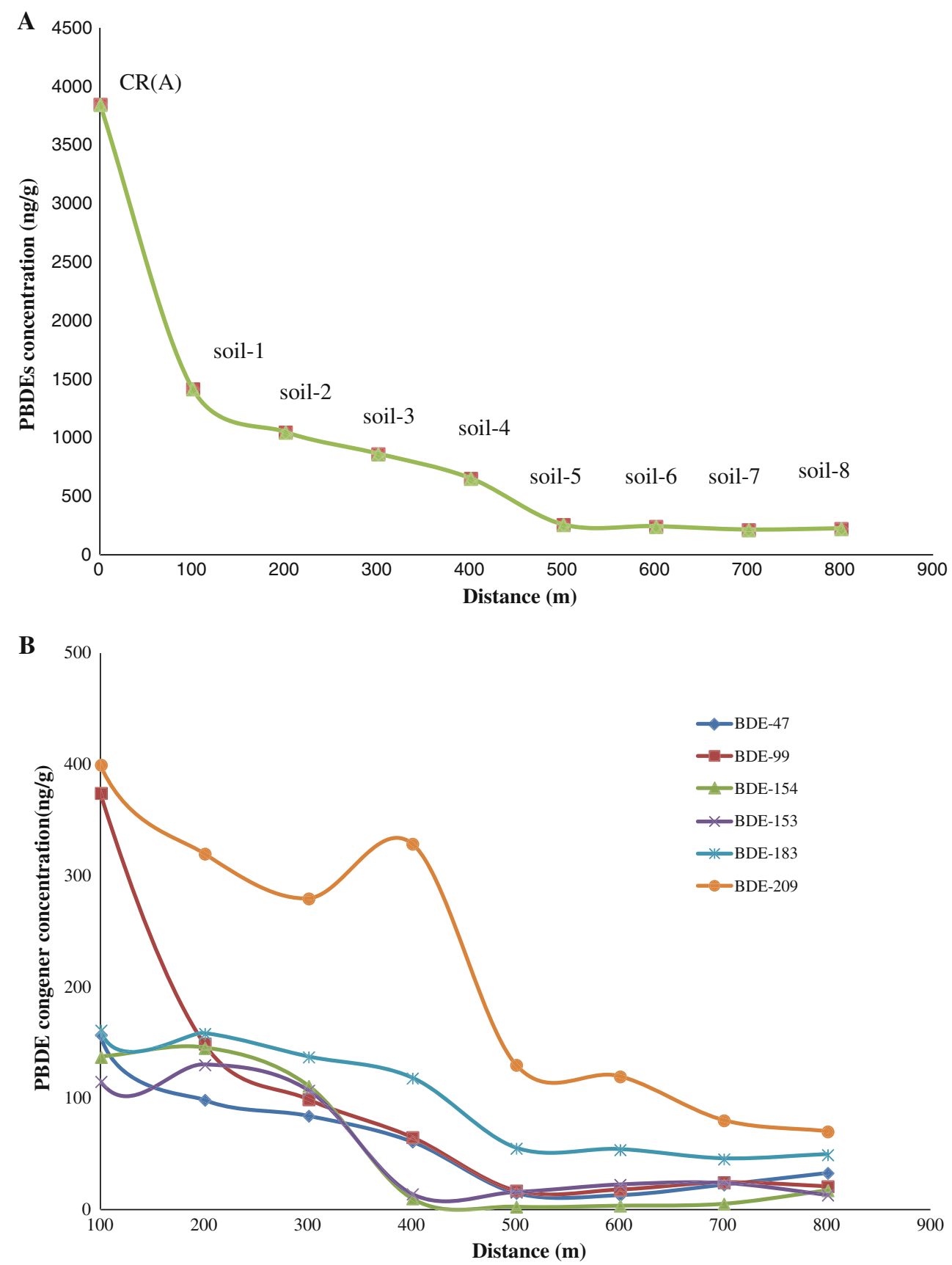

samples (Fig. 3). BDE-209, 183, 153, 154, 99, and 47 were also the major congeners detected in the soil samples. BDE-209 was the predominant congener consisting of $28.1 \%$ of the total PBDEs in S1 (concentration of $400.3 \mathrm{ng} / \mathrm{g}$ ) and $39 \%$ in S8 (concentration of $91.1 \mathrm{ng} / \mathrm{g}$ ). The percentage of BDE-209 was higher than $40 \%$ in S5, S6 and S7. The averaged proportion of BDE-209 in total PBDEs in soils (average $38 \%$ ) was greater than that in the burned combusted residues (average 17.1\%). However, the average absolute concentration of BDE-209 in soils (216.8 ng/g) was less than those in combusted residues (747.5 ng/g). BDE-183 was also detected at larger proportions (from $11.4 \%$ in S1 and $21.9 \%$ in S8), which was different from those detected in European background soils where BDE-183 was a minor contributor but BDE-47, $99,100,153$, and 154 were most frequently detected (Hassanin et al. 2004).

The concentrations of PBDEs and congener patterns in the samples collected from the open burning site were also different from those in soils collected from e-waste dumping sites (Wang et al. 2005; Cai and Jiang 2006). The open burning of computer casings and circuit boards stripped of metal parts may produce toxic fumes and ashes containing organic pollutants. This phenomenon was 
ascribed to heating or open burning during e-waste disposal, since PBDEs could be released when plastics containing brominated flame retardants were heated (Wong et al. 2007). The published data indicated that the PBDEs existed in the soil samples with concentrations up to $600 \mathrm{ng} / \mathrm{g}$ (dry weight) and tetra- (BDE-47), penta- (BDE99) and hexa-BDE (BDE-139, BDE-153, BDE-154) were the predominant isomers and its congener pattern was similar to a commercial penta-BDE formulation which probably resulted from the commercial penta-BDE product used in the fire retardants because the soil samples were collected in the vicinity of a site for the e-wastes disposal in Taizhou, Zhejiang (Cai and Jiang 2006). Results are different from PBDEs congener distributions in surface soil of an electronic waste dismantling site from Shenzhen, of which BDE-209 was the predominant (up to $85-99 \%$ of total PBDEs) (Qin et al. 2011). Uncontrolled disposal and recycling have apparently resulted in soil contamination with PBDEs. Higher brominated congeners (octa- and deca-BDEs) were also found with much greater concentrations in the samples from the open burning site in this study. This result is in line with other studies from the Pearl River Delta (PRD) where high BDE-209 concentrations were found in soils from the vicinity of PBDEs manufacturing sites (Luo et al. 2009; Qin et al. 2011).

The observed concentrations of PBDEs in the environmental samples indicated that the PBDEs contamination around the e-wastes open burning site in Guiyu is serious. The levels of PBDEs in environmental soil from Guiyu was about 1,000 times greater than those determined in soil samples collected near foam production facilities using the penta-BDE mixture as flame retardant in the UK and Norway (Harrad and Hunter 2006). Electronic wastes can cause major environmental contamination during the transportation, landfill, and incineration if not properly treated. Observations in soil samples from Guiyu indicated that uncontrolled open burning was one of the major sources of soil contamination of PBDEs.

As demonstrated in Fig. 4a, there was a general decline in concentrations of total PBDEs as a function of the distance from the combustion site (S1 to S8). The highest concentrations of PBDEs were detected in S1, collected from the site located closest to the open burning site and the soil with the lowest concentration was collected $800 \mathrm{~m}$ from the burning site. The total PBDE concentrations decreased dramatically with increasing distance from the burned site, suggesting that the combusted activities were the major source of PBDE contamination in the field. BDE209 concentrations generally decreased from the open burning site to the remote areas (S1 to S8) (Fig. 4b). Although BDE-47, 153, 154 and 183 have a similar decreasing trend to BDE-209, their reduced concentration ratios were much lower than that of BDE-209 (Fig. 4b).
The obtained data showed that PBDEs transportability of higher brominated congeners for short distances could differ from that of lower brominated congeners.

The distributions of PBDE congeners in soils were similar to those in combusted residues, partly because PBDEs are relatively stable in the air and soil (Lee et al. 2004). The obtained data on PBDEs concentrations and congener patterns suggested that the major contamination of PBDEs in soil might come from the combusted residue transportation and deposit. The soil samples close to open burning of e-waste were influenced by the combusted residue which contained high levels of PBDEs possibly because some soil sample had been collected directly below shredded pieces of printed circuit board. The obtained data might also suggest that the PBDE contamination in the soils from areas surrounding e-waste facilities mainly came from the e-waste recycling sites via air transport (Gao et al. 2011). However, the adsorption capacity to particle were various for different PBDE congeners. The particle size and direction of wind could change the settlement rate. It was obvious that PBDEs diffusion from the point pollution source has made the dominant contribution to PBDEs contamination in the surrounding regions.

\section{Conclusions}

The concentrations of PBDEs in combusted residues collected from the e-waste open burning site in Guiyu were much greater than those in soil samples. BDE-209, 183, $153,154,99$, and 47 that are the major components of commercial flame retardant products were detected in both combusted residue and soil samples in high concentrations. The total concentrations of PBDEs in the soil samples decreased with increasing distance from the e-wastes burning site. The results suggest that field soils might be contaminated by air transportation of combusted residues from e-waste incineration. The uncontrolled open burning of e-waste has resulted in serious environmental contamination of PBDEs.

Acknowledgments Financial support from the National Natural Science Foundation of China (NSFC21007077and NSFC21175025) and FRG2/11-12/118 is gratefully acknowledged.

\section{References}

Alaee M, Arias P, Sjodin A, Bergman A (2003) An overview of commercially used brominated flame retardants, their applications, their use patterns in different countries/regions and possible modes of release. Environ Int 29:683-689

Alcock RE, Sweetman AJ, Prevedouros K, Jones KC (2003) Understanding levels and trends of BDE-47 in the UK and 
North America: an assessment of principal reservoirs and source inputs. Environ Int 29:691-698

Betts K (2008) Does a key PBDE break down in the environment? Environ Sci Technol 42:6781

BSEF (Bromine Science and Environmental Forum) (2003) California State Assembly, Assembly Bill No 302, California State Assembly, Sacramento, CA www.bsef.com

Cai ZW, Jiang GB (2006) Determination of polybrominated diphenyl ethers in soil from e-waste recycling site. Talanta 70:88-90

de Wit CA (2002) An overview of brominated flame retardants in the environment. Chemosphere 46:583-624

Gao ST, Hong JW, Yu ZQ, Wang JZ, Yang GY, Sheng GY, Fu JM (2011) Polybrominated diphenyl ethers in surface soils from e-waste recycling areas and industrial areas in South China: concentration levels, congener profile, and inventory. Environ Toxicol Chem 30:2688-2696

Gill U, Chu I, Ryan JJ, Feeley M (2004) Polybrominated diphenyl ethers: human tissue levels and toxicology. Rev Environ Contam Toxicol 183:55-97

Gouin T, Harner T (2003) Modelling the environmental fate of the polybrominated diphenyl ethers. Environ Int 29:717-724

Hale RC, La Guardia MJ, Harvey E, Gaylor MO, Mainor TM (2006) Brominated flame retardant concentrations and trends in abiotic media. Chemosphere 64:181-186

Harrad S, Hunter S (2006) Concentrations of polybrominated diphenyl ethers in air and soil on a rural-urban transect across a major UK conurbation. Environ Sci Technol 40:4548-4553

Harrad S, Wijesekera R, Hunter S, Halliwell C, Baker R (2004) Preliminary assessment of UK human dietary and inhalation exposure to polybrominated diphenyl ethers. Environ Sci Technol 38:2345-2350

Hassanin A, Breivik K, Meijer SN, Steinnes E, Thomas GO, Jones $\mathrm{KC}$ (2004) PBDEs in European background soils: levels and factors controlling their distribution. Environ Sci Technol 38:738-745

Hites RA (2004) Polybrominated diphenyl ethers in the environment and in people: a meta-analysis of concentrations. Environ Sci Technol 38(4):945-956

Huang HL, Zhang SZ, Christie P, Wang S, Xie M (2010) Behavior of decabromo diphenyl ether (BDE-209) in the soil-plant system: uptake, translocation and metabolism in plants and dissipation in soil. Environ Sci Technol 44:663-667

Law RJ, Alaee M, Allchin CR, Boon JP, Lebeuf M, Lepom P, Stern GA (2003) Levels and trends of polybrominated diphenylethers and other brominated flame retardants in wildlife. Environ Int 29(6):757-770

Lee RGM, Thomas GO, Jones KC (2004) PBDEs in the atmosphere of three locations in Western Europe. Environ Sci Technol 38:699-706

Leung AOW, Luksemburg WJ, Wong AS, Wong MH (2007) Spatial distribution of polybrominated diphenyl ethers and polychlorinated dibenzo-p-dioxins and dibenzofurans in soil and combusted residue at Guiyu, an electronic waste recycling site in southeast China. Environ Sci Technol 41:2730-2737

Luo Q, Wong MH, Cai ZW (2007) Determination of polybrominated diphenyl ethers in freshwater fishes from a river polluted by e-wastes. Talanta 72:1644-1649

Luo Y, Luo XJ, Lin Z, Chen SJ, Liu J, Mai BX, Yang ZY (2009) Polybrominated diphenyl ethers in road and farmland soils from an e-waste recycling region in Southern China: concentrations, source profiles, and potential dispersion and deposition. Sci of Total Environ 407:1105-1113

Martin M, Lam PKS, Richardson BJ (2004) An Asian quandary: where have all of the PBDEs gone? Mar Pollut Bull 49:375-382

Mueller KE, Mueller-Spitz SR, Henry HF, Vonderheide AP, Soman RS, Kinkle BK, Shann JR (2006) Fate of pentabrominated diphenyl ethers in soil: abiotic sorption, plant uptake, and the impact of interspecific plant interactions. Environ Sci Technol 40:6662-6667

Palm A, Cousins IT, Mackay D, Tysklind M, Metcalfe C, Alaee M (2002) Assessing the environmental fate of chemicals of emerging concern: a case study of the polybrominated diphenyl ethers. Environ Pollut 117:195-213

Qin PH, Ni HG, Liu YS, Shi YH, Zeng H (2011) Occurrence, distribution, and source of polybrominated diphenyl ethers in soil and leaves from Shenzhen Special Economic Zone, China. Environ Monit Assess 174:259-270

Sjodin A, Jakobsson E, Kierkegaard A, Marsh G, Sellstrom U (1998) Gas chromatographic identification and quantification of polybrominated diphenyl ethers in a commercial product, Bromkal 70-5DE. J Chromatog A 82:83-89

Sjödin A, Päpke O, McGahee E, Jones RS, Lapeza CR, Focant JF (2004) Concentration of polybrominated diphenyl ethers (PBDEs) in house hold dust: inhalation a potential route of human exposure. Organohalogen Compd 66:3817-3822

Tang XJ, Shen CF, Shi DZ, Cheema SA, Khan MI, Zhang CK, Chen YX (2010) Heavy metal and persistent organic compound contamination in soil from Wenling: an emerging e-waste recycling city in Taizhou area, China. J Hazard Mater 173:653660

Terazono A, Murakami S, Abe N, Inanc B, Moriguchi Y, Sakai S et al (2006) Current status and research on E-waste issues in Asia. J Mater Cycles Waste 8:1-12

Wang DL, Cai ZW, Jiang GB, Leung A, Wong MH, Wong WK (2005) Determination of polybrominated diphenyl ethers in soil and sediment from an electronic waste recycling facility. Chemosphere 60:810-816

Wang S, Zhang SZ, Huang HL, Christie P (2011) Behavior of decabromodiphenyl ether (BDE-209) in soil: effects of rhizosphere and mycorrhizal colonization of ryegrass roots. Environ Pollut 159:749-753

Wong MH, Wu SC, Deng WJ, Yu XZ, Luo Q, Leung AOW, Wong CSC, Luksemburg WJ, Wong AS (2007) Export of toxic chemicals-A review of the case of uncontrolled electronic-waste recycling. Environ Pollut 149:131-140

Yu XZ, Gao Y, Wu SC, Zhang HB, Cheung KC, Wong MH (2006) Distribution of polycyclic aromatic hydrocarbons in soils at Guiyu area of China, affected by recycling of electronic waste using primitive technologies. Chemosphere 65:1500-1509

Zhang W, Wang H, Zhang R, Yu XZ, Qian PY, Wong MH (2010) Bacterial communities in PAH contaminated soils at an electronicwaste processing center in China. Ecotoxicology 19:96-104

Zhao YX, Qin XF, Li Y, Liu PY, Tian M, Yan SS, Qin ZF, Xu XB, Yang YJ (2009) Diffusion of polybrominated diphenyl ether (PBDE) from an e-waste recycling area to the surrounding regions in Southeast China. Chemosphere 76:1470-1476

Zou MY, Ran Y, Gong J, Maw BX, Zeng EY (2007) Polybrominated diphenyl ethers in watershed soils of the Pearl River Delta, China: occurrence, inventory, and fate. Environ Sci Technol 41:8262-8267 